\title{
From Cherry Picking to Convergence - Migrating E-Learning Delivery to an LMS (Learning Management System) - the COLeLIO Experience
}

http://dx.doi.org/10.3991/ijac.v5i3.2192

\author{
Angela Kwan \\ Commonwealth of Learning, Vancouver, Canada
}

\begin{abstract}
The Commonwealth of Learning e-learning for International Organizations (COLeLIO) (www.col.org/colelio) Initiative engages appropriate technology to custom design and deliver just-in-time (JIT) workplace e-learning for adult learners based in field offices and headquarters of international organizations spread all over the world. To ensure reliable and easy access to learning, COLeLIO chooses appropriate technologies to underpin course design, development and delivery taking into consideration bandwidth and access issues. Responding to constantly changing learning environments and learners' needs, eLIO learning materials have evolved from print to digital over the last decade. In recent years, eLIO saw the need to streamline the delivery operation for their 1,000 learners annually, involving 40 tutors and teams of course administrators. Recognizing that the conduits supporting online learning have mushroomed in recent years and that more affordable and robust open source learning management platforms are available to support and sustain online learning for transparency, accountability and quality results, COLeLIO spent 12 months searching for and adapting a technology solution to create a one-stop access to resources, support, discussions, and records for learners, tutors and administrators. This paper captures the story of change management by eLIO and shares some key lessons learned.
\end{abstract}

Index Terms_ E-Learning, LMS, ODL.

\section{INTRODUCTION- MASTERING TwO POLARITIES}

COLeLIO believes that to provide quality workplace elearning to staff working in international organizations, two principles are of paramount importance. They are:

- $\quad$ To adhere to open and distance learning (ODL) best practice

(http://www.col.org/progServ/panComm/virtualConf erences/Pages/2004bestPractice.aspx) that is when teacher and learners are separated learning can happen effectively through contextualized and customized content, support and logistics; and

- To select the appropriate technologies to enable learning.
Adhering to ODL best practice and producing highly customized course content supported by personal tutoring is the constant while technology the variable in the elearning winning formula. They are like the "yin" and "yang" that Dean Anderson alluded to in his Beyond Change Management (2010) that in order to excel at anything one must master at least one of two polarities. The three pillars of ODL best practice are: andragogy (how well adults learn), support (what help do they need) and logistics (how to reach learners with timely learning resources and support). COL eLIO applies these three pillars by ensuring that learners receive tailored courses relevant to their work context; by assigning a personal e-tutor to each learner; and finding a suitable mode of technology for course delivery. For e-learning programs to work, no matter whether they are produced in print, multi-media, or on-line, designers and developers must build a course with a strong foundation in these three pillars of e-learning.

Technology is the variable because by nature it changes all the time in terms of speed, capacity, and ubiquity. Learning through technology has caused a paradigm shift in the speed, scope and scale of learning. It enables massive learning to happen across time, geography and space seamlessly and quickly.

Having provided tutor and technology-mediated learning to a number of international organizations over a decade, the COLeLIO experience underscores that the excellence of e-learning is about treating ODL and technology with equal care and gravity. However, as technology is going through such a dynamic period of exponential growth, its glitziness and limelight often casts a shadow over the three pillars of ODL.

According to Shank (2008), e-learning suffers from a strong case of hyperbole because of the hype and claim of technology in learning without due regard to the use of technology within the broader context of learners, instructors, learning environment and society. Indeed, it is very easy for course content and the practicalities of supporting e-learning to get lost in the shuffle to upgrade e-courses to the newest and most popular mode of 
technology. On the other hand embracing only the ODL pillars without harnessing the power and potential of technology is also a dis-service to the $21^{\text {st }}$ century learners, described by Marc Prensky (2001) as the digital natives - many of whom were born after the obsolescence of typewriters! Over the years, COLeLIO has been trying to achieve the desired balance of optimizing e-course quality and outcomes with the most suitable technological delivery method for its e-learners. Increasingly, the best technological choice has been using Learning Management Systems (LMS), and the transition of our ecourses to LMS has been a sometimes challenging, yet interesting journey.

\section{FROM GOOD TO GREAT}

When COLeLIO first delivered Writing Effectively online for UNHCR at the turn of the century, tutor emails to learners based in Kandahar in Afghanistan went through radio dial up. Emails could not exceed a hundred words and could not support assignment attachments in Word files. Learners had to find a learning buddy in Kabul to redirect emails from tutors; to forward assignments and to post marked assignments by snail mail from Kandahar to Kabul.

Against this technology backdrop, COLeLIO carefully chose the lowest denomination of technology to ensure the widest reach of learners based in remote locations. In the early 2000's, most COLeLIO course materials were either stand-alone paper manuals or CD-ROMS mailed to learners dispersed in field offices. Since 2006, learners have had the options to access materials from either the eLIO content hosting site on the web, the CD-ROM or to print from either of the sources. Despite the distance nature of these courses, an effort was made to engage each learner in a personal way. The personal tutors that each learner was assigned put a face and a human touch to the learning process. The tutoring support was primarily done by emails where tutors communicated with learners one-on-one. All assignments were submitted as email attachments. Then and now, tutormarked-assignments (TMAs) are required to be discursive, developmental and deep. They act as knowledge and thoughts exchange vehicles for capacity enhancement and empowerment. Tutors assessed the submissions using track changes and highlight comments to engage learners in a dialogue and the evidence of learning is often a trail of assignments submitted, once, twice and thrice. At the end of the course, tutors were required to zip and submit all TMAs to COL for learner records and for monitoring and evaluation purposes. To ensure that every learner receives detailed and constructive feedback on their assignments, COLeLIO randomly selected TMAs for quality assurance and standardization purposes. Another tutor obligation was to provide COLeLIO administration with Monthly Progress Reports (MPRs) to report on where learners are at with assignments submission which allowed the team to see the monthly progress of each learner. If an MPR revealed a learner was falling behind, then immediate action could be taken by the COLeLIO team to get the learner back on track.

After a decade, the eLIO team, its cadre of distance tutors and most of the adult learners became comfortable with this delivery design. However, as the operation grew and learner numbers tripled from its initial size of 300 learners a year, the emailing back and forth of assignments, MPRs, TMAs and communications became a burden to the small eLIO team. Concurrently, the development of learning management systems (LMS) was looming and there were sporadic instances where COLeLIO has been offered the opportunity to try out different platforms like A-tutor, Fronter and customized OASS (Online Assignment Submission System). While none of these systems seemed perfectly suited to the needs of the e-courses at that time, they did reveal some exciting new possibilities in course delivery.

In 2005 the eLIO team started the change management discussion. The team agreed that the digital footprints of LMS could help the initiative to move from good to great. But it wasn't until a series of events took place that COLeLIO finally arrived at a new stage of course delivery convergence where learners, tutors and administrators from all four corners of the world are brought together to interact in one virtual platform. Our continuing journey to this state of convergence is primarily a story of change management.

The transitional change (see diagram below) described by Dean Anderson which is the design and implementation of a desired new state that solves an old state problem; requires management of the transition process to dismantle the old state while putting in place the new state; managed timetable.

Figure 1: Transitional Change

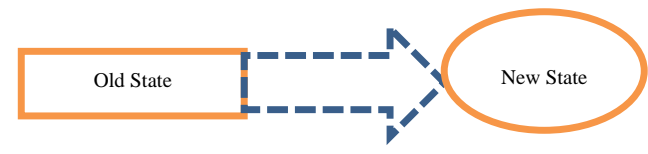

\section{THE ROADMAP TO CHANGE}

The model of transitional change is quite complex as it does not improve what is, but replaces what is with something entirely different. Also the process of change is operated within a tight budget and timeline. As with any change process people dynamics is key to making or breaking the realization of the new state. Along with needing to gain new knowledge and develop new skills, people often must change or develop new behaviors as well. As COLeLIO moved towards delivering all ecourses through an LMS, several key transitional change strategies described by Anderson were followed to ensure that the critical impacts of the change - organizational and humans- can be dealt with effectively. They were: 
- Well - communicated case for change

- A clear change plan

- User involvement in designing and implementing the plan

- Control of implementation

- Workload and capacity management

- A sound training plan

- Adequate support and integration time

COLeLIO set the overarching goals for converging course delivery on an LMS to:

- Improve on delivery effectiveness and efficiency; and

- Enrich course participants’ learning experience

The roadmap to change is a nine-step process described by Dean as in the following diagram:

Figure 2. Nine-step process

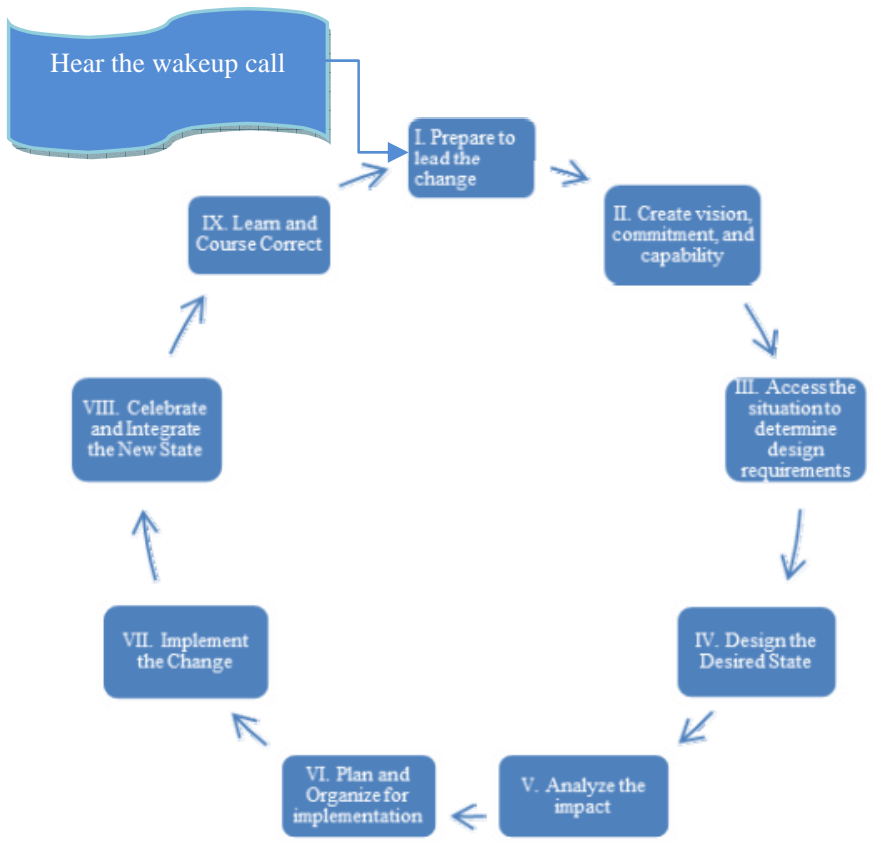

The opportunity lent itself to kick start the LMS change process that COLeLIO envisioned when COL set up a Moodle (open source) LMS in 2009 to support organization-wide course development and delivery

COLeLIO latched on this development to implement course delivery on Moodle. In considering the change plan and processes, eLIO decided not to impose changes on ongoing courses (involving close to 1,000 learners) as it would be very disruptive and hard to manage. As there was a brand new course under discussion and development, the team proposed with the support of the Commonwealth Secretariat that the new Debt Recording and Management (DRM) e-learning course would be designed and delivered on Moodle. A Moodle expert was consulted to capacitate the team with the required knowledge and zests to prepare for the change. The development team considered the curriculum and assessment needs of DRM and employed and integrated Moodle features from the beginning when organizing and designing the course. Many Moodle features were incorporated including: forum for group discussions, quizzes for comprehensive assessment, e-mail for one-onone tutoring, uploading and downloading assignment submissions, bulletin boards for class broadcasts and grader feature for entering grades and creating transcripts. Trialing DRM on Moodle established a blueprint of what the "new state" of converging learning delivery on a platform could look like.

With the development of this new course on an LMS, the vision of a truly virtual global classroom where learners, tutors, and administrators could interact in one space became a reality. The allocation of various user rights to different groups, and the password controlled access provides the order and the security for interaction in this virtual space.

The DMS site on Moodle supports three groups of users, namely;

- Learner access to his/her own assignments, grades, and to what is commonly accessible to all learners like course materials, assignments, learning resources, online quiz, group forum, bulletin board, calendar, emails with personal tutor and group members.

- $\quad$ Tutor access to his/her group of learners to read their assignments, upload TMAs, record grades, send emails, moderate group forum discussions and to what is commonly accessible to all tutors like tutor forum, MPRs and tutor resources.

- COLeLIO's access to all of the above including a whole range of user reports made available on Moodle. This increase in administrative oversight has made it possible for the admin team to assist the tutors and learners in a more timely fashion.

- The Moodle expert COLeLIO hired is the gold nugget in the change process. He showed the team how to build Moodle classes; tested the DMS site; fixed bugs on the go, prepared "How to" guides for users (e.g. learners - how to upload assignments for marking; tutors - how to download assignments for marking and how to upload TMAs for learner record and access.), and monitored the trial run of DMS on Moodle.

- DMS tutors were newly recruits for the new course on Moodle, and many of the learners were experiencing online learning for the first time. There were no old habits to break and all of them - the tutors and learners, based in the developing Commonwealth countries were excited to experience e-learning conducted via a virtual platform. 
- To prepare the tutors for DMS Moodle a "sandbox" was created for tutors to try out Moodle functions and familiarize with the environment. To take care of the learners, a Moodle orientation week was introduced prior to the course start date. During the week, learners were given login instructions and a "Mastering Moodle" sheet wherein seven simple tasks were listed for the learners to complete as a means to help them navigate through the virtual platform (see documents in the attachment). Also tutors and COL administrators were on standby to field learners' questions.

COLeLIO organized the evaluation of the pilot cohort to seek answers to the effectiveness of the Moodle system for communication, interaction, support, and assessment. The result showed that $78 \%$ of the DMS pilot learners responded positively to the experience. Tutors did mention that they went through a learning curve in Moodle and whenever access was unstable they reverted to standard emails to reach their learners. With an overall completion rate of $84 \%$ for the DMS pilot on Moodle, COLeLIO was confident to charge ahead with the transitional change on their existing courses.

The DMS pilot represented 5\% of the eLIO operation. $95 \%$ of the operation was still in the "old state" of email reliance. Moving operations from the old to the new state would be more difficult as it meant changing the behavior of close to 40 active tutors well-versed in the old model of doing things and very comfortable with the status quo.

The team looked at the various long-standing courses and decided that the next course to move into Moodle would be Writing Emails, Memos and Letters online (WEML). This group was selected because the cohort size of 50-70 was ideal, the course design was simpler, and the partnering organization fully supported the idea.

A face-to-face professional enrichment meeting of all tutors in October, 2009 provided the forum for eLIO to describe this new reality. Tutors' initial reception was mixed. Some were cautiously open and would not mind trying; others were apprehensive and asked "Why fix something not broken?" However, all accepted that the change would be made. Upon the successful completion of the DMS pilot in Moodle in April 2010, COLeLIO set up a Moodle sandbox and invited all WEML tutors to try it out get a feel of what it was like to tutor in Moodle. This exposure was supported by an online forum in Moodle to encourage wide sharing of the Moodle experience. Concerns about Moodle being a barrier to learning and likely breach of security and confidentiality were expressed at that time.

Dean's multidimensional process approach suggests that the key lever for delivering change results is people and their reaction to change. Often they are affected by the four quadrants of mindset (internal, individual); culture (internal, collective); behavior (external, individual), and systems (external, collective). Many times change fails because of people's resistance. Until this resistance can be unlocked and turn into commitment, there is no guarantee of success. People's resistance to change is naturally triggered when anyone of the six core needs namely: security, inclusion and connection, power, control, competence and justice and fairness are threatened.

Before the start of the WEML trial, we explained to tutors the rationale behind the transitional change process, assured tutors that the trialing would be evaluated and studied carefully and that tutors' and learners' feedback would be taken seriously before any final decisions of the "new state" would be made. We also depicted what benefits the "new state" would bring to tutors:

- One-stop access to study materials, learning resources, course information, assignment, grades, and support by learners, tutors and administrators.

- $\quad$ Time saving in record keeping. With Moodle there is no need to file every email and every assignment for each learner as a complete record to present to COL. Emails and TMAs are all lodged in Moodle for learners and COL's access.

- $\quad$ Effort saving in MPRs. We used Wiki to set up MPRs for tutors in Moodle. All that tutors needed to do prior to submitting MPRs is scan through each learner record on Moodle and then fill out the MPR in two words "on track", "no issues" or "follow up".

- Streamline communication through group forums. With the group forum in Moodle, tutors can share messages and post reminders of common concerns and issues rapidly. They can also seek peer to peer advice through tutor forums.

- Reduction in administrative time would free up tutoring time to focus on learner and learning issues

COLeLIO decided to test the transitional change with the WEML cohort starting in November 2010. The COL team prepared a detailed check list for:

- Preparing learners, tutors and administrators for interacting and navigating in the Moodle environment

- Testing the robustness of each functions,

- Orientating learners

- Organizing a response team to provide support during weekdays and weekends

Unfortunately, WEML in Moodle proved to be more challenging than DMR. First the former cohort size was double that of the latter. Second, tutors struggled with letting go of old habits and practices. Third, the Moodle backbone against which the WEML class sat was not in sync with eLIO's specification. COLeLIO realized from this trial that communicating with the organizational IT provider that hosted the Moodle site to support course activities was very important. When the organizational link faltered, the whole change process can flounder. 
Two Moodle focus surveys (one for learners and one for tutors) were held at the end of WEML to gauge users' satisfaction and experience. An interesting point to note is that learners were more positive about Moodle than tutors. It is understandable because learners only reference point was the Moodle new state and there was no old state to compare with. Both learners and tutors were asked the following questions:

- The MOODLE learning platform was easy to use when the course started. Strongly Agree/Agree/Neither Agree nor Disagree/ Disagree

- The MOODLE learning platform is easy to use now. Strongly Agree/Agree/Neither Agree or Disagree/Disagree/Strongly Disagree

There was a 3\% improvement in the learner group strongly agreeing to the latter statement whereas improvement was of $30 \%$ in the tutor group which shows that more tutors struggled with Moodle when they first used the platform. eLIO reflected on this reaction from tutors and felt that more attention should have been provided to the capacity management of tutors in adapting to the new tools and processes in Moodle.

COLeLIO concluded with the following Moodle recommendation after the WEML trail:

COL made a progress check by course mid-point comparing assignment submission rate via MOODLE and outside MOODLE between two November cohorts (WEML 4 and WEML 6). There is an improvement in assignment submission rate via MOODLE. The overall feedback COL gathered is that the virtual platform is worth keeping despite some of the start-up glitches nagging both learners and tutors. The value of MOODLE cannot be overlooked in that:

- $\quad$ it keeps everything in one place for learners i.e. the reading, reflecting, communicating, and accessing data/resources; and

- it is web-based application enables greater access flexibility, attracts less spam and allows more interactions between course learners.

\section{The Result OF CONVERGENCE}

Twelve (12) months after the WEML pilot, all eLIO courses are now either delivered or administered via the Moodle LMS. About 30 to $40 \%$ of the eLIO courses are fully operational on Moodle, i.e. learners, tutors, and administrators are interacting through the virtual space. The remaining $60 \%$ consists of courses run either in other agencies' LMS or only the tutors are using Moodle for keeping learner records, grades and assignments. The reason for a delay in the full scale implementation is that large cohorts of over 100 will require more time to ensure the following three points are addressed before the transitional change can be completed:

- People (both tutors and learners) readiness and engagement

- Stable and adequate infra-structural capacity to support activities on Moodle at scale

- A bi-lingual Moodle to support both English and French cohorts

What has converging learning, supporting and organizing on Moodle achieved? So far learners have said positive things about Moodle e.g. "The MOODLE is a great learning tool and it's a must to everyone.” Tutors' also feel that Moodle has grown on them and they are happier tutoring in Moodle now. With the streamlining of administration in Moodle, the eLIO team of three is able to do more with no increase in administrative support and is able to generate better training results and reports from exporting files from Moodle.

\section{The Lessons Learned}

Dean and Linda Ackerman Anderson stressed that the critical areas for successful change and breakthrough are content, people and process. COLeLIO learned that staying on course is important in what needs to be changed. The course from start to end is about putting learner in the center of content, support and logistics which Moodle helps to reinforce. In transforming people and process through steps 1 to 9 of the roadmap, eLIO never wavered from the conviction that, once people overcame the initial learning curve and saw the strengths of the new state, no one would want to go back to the old and mundane way of doing things. Also many tutors and adult learners might not be digital natives by birth, but over time some migrants are empowered to be natives equal. We are always listening to Moodle users for feedback and improvement. The eLIO Moodle Administrator has developed her own instance creation manual which is a log of "dos" and "don'ts" and a list of improvements to be implemented in the next Moodle instance. Furthermore, as our existing courses go through updates in the future, Moodle features can be more seamlessly integrated into them. Integrating LMS from the beginning, as opposed to tacking it on to a preexisting course is the key to success as evidenced by COLELIO's two experiences with the DRM and WEML courses.

\section{The Future}

In the next triennium, eLIO will remain to be a workplace e-learning responsive unit working with international organizations to provide just-in-time professional development to widely dispersed colleagues all over the world. It will continue to harness the growing power and richness of learning platforms to integrate learners, tutors and administrators for a quality capacity enhancement experience that is relevant, practical and applicable. 
Moodle is one tested tool in the convergence experience; other tools will be discovered and explored as appropriate like e-portfolio, e-journal, smartphone and iPhone applications for e-learning. The future continues to look exciting and unpredictable. Whatever new state eLIO will arrive at through the current change exercise, more new states will emerge requiring change management strategies to produce desirable transformations in the age of digital learning.

\section{REFERENCES}

[1] D. Anderson and L.A. Anderson, Beyond Change Management, $2^{\text {nd }}$ ed., Pfeiffer: A Wiley imprint, 2010, pp.6, 53,147, \& 240

[2] M. Prensky On the Horizon (MCB University Press, Vol. 9 No. 5, October 2001)

[3] S. Carliner and P. Shank, The e-Learning Handbook, Pfeiffer: A Wiley Imprint, 2008, pp. 16 to 24
[4] Commonwealth of Learning (2010) Pilot Completion Report CSDRMS eLearning, June. Commonwealth fo Learning, Vancouver, Canada.

[5] Commonwealth of Learning (2010) Course Completion Report, May. Commonwealth of Learning, Vancouver, Canada.

\section{AUTHOR}

Angela Kwan is with the Commonwealth of Learning, Vancouver, BC V6E 2E9 CANADA (e-mail: akwan@col.org).

This article is an extended version of a paper presented at the conference ICELW2012, held June 2012, at Columbia University, in New York, NY, USA. Manuscript received 30 March 2012. Published as resubmitted by the author 5 August 2012. 


\section{Attachment}

First Time Accessing the COL MOODLE website

Step 1. Type this URL address into your navigation/address bar and press enter: http://www.col-vle.org/course/view.php?id=xxx

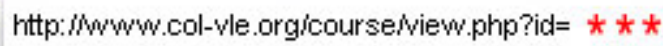

Step 2. Enter your "Username" and "Password" and then select "Login".

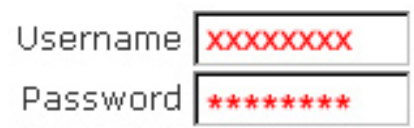

Login

Note: Usernames \& Passwords are case sensitive.

Step 3. Your temporary password must be changed in order to proceed.

Make up a new password that you can remember.

\begin{tabular}{|c|c|}
\hline Username & $x \times x x x x x x x x x x$ \\
\hline Current Password* & $* * * * * * * *$ \\
\hline New password* & $* * * * * * * * *$ \\
\hline New password (again)* & $* * * * * * * * *$ \\
\hline
\end{tabular}

Step 4. Your password has been changed.

Press continue.

Continue

Step 5. Once enrolled, you will find yourself inside your course

homepage.

Read the instructions carefully.

Press “Save changes”.
Assistance

For assistance logging in, please contact your tutor.

For technical support for login issues, please contact the

COL e-Learning Helpdesk at colvle-helpdesk@col.org

We will usually respond within one to two business days. 


\section{MOODLE Information Sheet}

There are certain functions and links in MOODLE you will use often. An explanation of each of these functions is provided below in alphabetical order:

\section{Assignment}

In section 3 of the center column, you will see Submission of Assignments. Please click on the right link for each of your assignment submission. There is another assignment button on the left hand activity column. If you click on that, it will show your assignment submission progress on one page.

As soon as you have uploaded your assignment, your tutor will be notified. When your tutor has marked your assignment and uploaded her feedback to MOODLE, you will be notified by e-mail. Sometimes these MOODLE notifications will go to your spam/junk folder, so please check those folders regularly.

\section{Bulletin Board}

The Bulletin Board is the location where the Commonwealth of Learning (COL) posts important, course-related information. When COL posts a message on the bulletin board, you will receive a notification in your e-mail inbox. The message will also be captured in the Latest News on the right hand column below the E-mail List.

\section{Course Information}

COL has posted four PDF files (Key Dates, Course Regulations and Guidelines, Frequently Asked Questions, and Guidelines for Studying at a Distance) there. Before the course begins, please read each PDF file carefully. They are important documents to guide your online learning.

\section{E-Learning Forum}

The e-Learning Forum is a group chat room for you, your tutor, and your fellow group participants. You can post general discussion questions here and read what other learners and tutors have posted. Messages posted there will be visible to the whole group and are archived according to subject heading.

\section{E-mail function in MOODLE}

MOODLE e-mail operates like any e-mail account, with one difference. You can only e-mail people registered in your group i.e. your personal tutor, your group participants, and the COL team. When someone sends you an e-mail through MOODLE, you will get a notification in your office e-mail. To open the e-mail, you need to $\log$ in to the COL MOODLE site using your own username and password.

\section{Grades}

Click on Grades to keep track of your assignment results (i.e. satisfactory, in progress and incomplete) and your overall course grade (successfully complete, not successfully complete - charge, and not successfully complete - no charge). Your grades are only visible to you, your personal tutor, and COL administration.

\section{MOODLE How To Guides}

There are four PDF files (MOODLE Navigation Guide, Guide to edit your Personal Profile, Guide to use MOODLE E-mail List, and Guide to Upload your Assignment on MOODLE) to help you navigate through MOODLE in case you need more information to do it. Please refer to them whenever necessary. If you still have questions, please consult your personal tutor. 


\section{Mastering MOODLE}

Please do the following simple tasks and you will see how easy it is to navigate around and use MOODLE.

\section{Task One - Update your personal profile}

1. Click on your name in the top right hand corner. You cannot change your first name, last name, or email address.

2. Add a short description of yourself by clicking "edit profile" and typing in the box provided.

3. Change the city, town, and country to your present location.

4. Click the "update profile" button at the bottom of the page to save your changes/updates.

\section{Task Two - Add your own picture to your profile}

1. Click "edit profile".

2. Scroll down to "picture of".

3. Select the "browse" button to locate a desired image (a head-shot is recommended) from your computer. Be sure the file for the image you want to use is less than $8 \mathrm{MB}$ in size.

4. Enter a description of the image (i.e. your name).

5. Click the "update profile" button.

Task Three - Look for your personal tutor and your group

1. On the cohort home page, click "Compose" under "E-mail list" in the top right hand corner.

2. Click "contact" and you will see your tutor and your group participants who have signed up on MOODLE.

3. Type a Subject (i.e. Hello group) and a brief message.

4. Click send.

Task Four - Post a message on the learning forum of your group
1. On the cohort home page, under "Learner Resources", click on "Learning Forum"

2. Click on "Add a new discussion topic" button

3. Type your subject and introductory message to your tutor and group participants. Your message will be sent to your group email inbox and is archived and threaded in the Learning Forum following the message title.

4. Click "Post to forum" to send your message.

Task Five - Send an e-mail to me (Angela Kwan) and your personal tutor

1. On the cohort home page, under Email List in the top right hand corner, click on "Compose".

2. Click on "Contacts...".

3. Click on "To" beside your tutor's name.

4. Click "Cc" beside my name (Angela Kwan).

5. Click "Cc".

6. Click "Close this window".

7. Type the subject and a brief email and click the "Send" button.

Task Six - Set automatic e-mail alerts in your regular e-mail

1. Click on E-mail List on the right side of the MOODLE window

2. Click on Inbox and then on Settings (in the top right corner of the window).

3. Select Yes for "Do you want to receive alerts on your email?"

4. Click save changes 